\title{
O ARMAZENAMENTO REFRIGERADO PROLONGA A VIABILIDADE DE SEMENTES DE GOIABEIRA-SERRANA ${ }^{1}$
}

\author{
JOEL DONAZZOLO ${ }^{2}$, THIAGO SANCHES ORNELLAS 3 , LEON BIZZOCCHI ${ }^{4}$, \\ VINICIUS VILPERTE ${ }^{3}$, RUBENS ONOFRE NODARI ${ }^{5}$
}

RESUMO- Este trabalho teve como objetivo avaliar a viabilidade e o vigor das sementes de dois genótipos de Acca sellowiana sob diferentes condições e tempos de armazenamento. As sementes foram obtidas a partir de duas plantas (G1 e G2) localizadas em quintais da área urbana de Vacaria-RS. O experimento foi realizado em esquema trifatorial $(2 \times 3 \times 2)$, sendo duas condições de armazenamento (temperatura ambiente: $20-25^{\circ} \mathrm{C}$; e refrigerado: $4-8^{\circ} \mathrm{C}$ ), três períodos de armazenamento (zero, um e dois anos), e dois genótipos (G1 e G2), conduzidos em blocos casualizados, com quatro repetições de 50 sementes. As sementes foram postas para germinar sobre papel absorvente umedecido em caixas tipo "gerbox", mantidas em câmara de crescimento com temperatura de $25 \pm 2{ }^{\circ} \mathrm{C}$ e fotoperíodo de $16 \mathrm{~h}$. Avaliaram-se o índice de velocidade de germinação, a porcentagem de germinação e o tempo médio de germinação, por meio da contagem de sementes germinadas a cada dois dias, por 44 dias após o início da germinação. Os genótipos apresentaram desempenhos significativamente diferentes na taxa germinativa e no vigor das sementes. Quando armazenadas em temperatura ambiente, as sementes perderam o poder germinativo drasticamente no primeiro ano e completamente no segundo ano. Conclui-se que é possível manter $80 \%$ de poder germinativo das sementes de Acca sellowiana por dois anos em armazenamento refrigerado $\left(4\right.$ a $\left.8{ }^{\circ} \mathrm{C}\right)$.

Termos para indexação: Feijoa, Acca sellowiana, conservação de sementes, teste de germinação, vigor de plântulas.

\section{THE COLD STORAGE PROLONGS THE VIABILITY OF FEIJOA SEEDS}

748ABSTRACT - This study aimed to evaluate the viability and seeds vigour of two genotypes of Acca sellowiana under different conditions and storage time. The seeds were obtained from two plants (G1 and G2) located in the backyards of the urban area of Vacaria city from the state of Rio Grande do Sul. The experiment was conducted in trifatorial design $(2 \times 3 \times 2)$, two storage conditions (room temperature: $20-25^{\circ} \mathrm{C}$; and cool: $4-8^{\circ} \mathrm{C}$ ), three storage periods (zero, one and two years), and two genotypes (G1 and G2) arranged in randomized complete blocks design with four replications of 50 seeds in each plot. The seeds were germinated over dampened paper towel in gerbox and kept in "fitotron" with a temperature of $25 \pm 2^{\circ} \mathrm{C}$ and a photoperiod of $16 \mathrm{~h}$. It was assessed the germination speed index, percentage of germination and mean germination time, through counting of germinated seeds every two days during 44 days after onset of germination. The genotypes had significantly different performances in germination rate and vigour of the seeds. When stored in environment temperature the seeds lost the germinal vigour dramatically in the first year and completely in the second year. It is concluded that it is possible to maintain $80 \%$ of germination of Acca sellowiana seeds for two years in cold storage (4 to $8^{\circ}$ C).

Index terms: Pineapple-guava, Acca sellowiana, seed conservation, germination test, seedling vigour.

\footnotetext{
(Trabalho 179-14). Recebido em: 06-06-2014. Aceito para publicação em : 17-10-2014.

${ }^{2}$ Professor da Universidade Tecnológica Federal do Paraná, Campus Dois Vizinhos, Estrada para Boa Esperança, km 04, Caixa Postal 157, Dois Vizinhos-PR, CEP 85660-000. E-mail: joel@utfpr.edu.br.

${ }^{3}$ Mestrando do PPGRGV/UFSC, Florianópolis-SC, Brasil.E-mails: thisorn@gmail.com; vilperte@gmail.com

${ }^{4}$ Eng. Agr., MSc. em Recursos Genéticos Vegetais. E-mail: leon.bizzocchi@gmail.com

${ }^{5}$ Professor Titular PPGRGV/CCA/UFSC, Florianópolis-SC, Brasil. E-mail: rubens.nodari@ufsc.br.
} 


\section{INTRODUÇÃO}

A Acca sellowiana O. Berg é uma Myrtaceae nativa do Sul do Brasil, norte do Uruguai (MATTOS, 1986) e noroeste da Argentina (KELLER; TRESSENS, 2007), conhecida popularmente por goiabeira-serrana, goiabeira-do-mato, goiabeirada-serra e feijoa. A planta possui grande potencial de uso alimentar, medicinal, recuperação de áreas degradadas e ornamental (MATTOS, 1986; VUOTTO et al., 2000; BONTEMPO et al., 2007; SAZIMA; SAZIMA, 2007; SANTOS et al., 2009).

Estudos ligados à biologia da espécie, ao avanço no processo de sua domesticação e à ampliação do uso no centro de origem vêm sendo conduzidos (NODARI et al., 2008). Fora do centro de origem, a espécie é cultivada em vários países, sendo a Nova Zelândia e a Colômbia os maiores produtores mundiais (THORP; BIELESKI, 2002). Contudo, a planta ainda pode ser considerada de domesticação incipiente em seu centro de origem (SANTOS et al., 2009; NODARI et al., 2008), havendo lacunas sobre o conhecimento de sua biologia, as quais podem interferir no avanço do uso sustentável da espécie. Ainda não está claramente definida a viabilidade da conservação de suas sementes por longos períodos. Porém, o uso de sementes posterior à colheita é crescente, seja para fins de conservação ex situ, seja como meio de multiplicar a espécie para uso direto, seja para obter populações segregantes para fins de melhoramento genético e outros estudos.

Pammenter e Berjak (1999) consideram que existem diferentes níveis de recalcitrância em sementes, o que é importante para a definição de diferentes estratégias de conservação ex situ de germoplasma. As sementes de goiabeira-serrana foram recentemente classificadas fisiologicamente como intermediárias por tolerarem o dessecamento até 5\% de umidade, contudo não tolerando o armazenamento a frio (GOMES et al., 2013). Outras espécies de mirtáceas do Sul do Brasil podem ter comportamento intermediário (Psidium cattleyanum Sabine) ou recalcitrante (Eugenia involucrata, DC, E. uniflora e Myrcianthes pungens (O.Berg) Legrand) (WIELEWICHI et al., 2006). Em geral, sementes das espécies de Eugenia são sensíveis à redução de umidade abaixo de $45 \%$ e perdem a viabilidade com teor de água entre 15 e 20\% (DELGADO; BARBEDO, 2007).

Pouco se conhece sobre aspectos relacionados à viabilidade de armazenamento tanto a curto quanto a longo prazos de sementes de $A$. sellowiana. Quando com frutos maduros, as sementes de A. sellowiana apresentaram $21 \%$ de umidade, a germinação foi superior a 75\% e com características de serem fotoblásticas positivas (SANTOS et al., 2004). Mattos (1986) também afirma que a espécie apresenta altas taxas de germinação, que é do tipo epígea. Porém, considerou de curta viabilidade, recomendando que sejam semeadas logo após sua extração dos frutos. Quando as sementes de $A$. sellowiana foram armazenadas a $8{ }^{\circ} \mathrm{C}$ em saco de polietileno, perderam gradativamente o potencial germinativo inicial de $90 \%$, o qual se reduziu pela metade aos 90 dias (GOMES et al., 2013). Contudo, após seis meses de armazenamento refrigerado a 8 ${ }^{\circ} \mathrm{C}$ em embalagem aluminizada e selada, as sementes apresentaram mais de $90 \%$ de germinação (FAIAD et al., 2003). Ainda é desconhecida a viabilidade de sementes armazenadas por tempos maiores do que os citados.

O objetivo deste trabalho foi avaliar a influência das condições e do tempo de armazenamento de sementes de dois genótipos de Acca sellowiana sobre a viabilidade das sementes e o vigor das plântulas.

\section{MATERIAL E MÉTODOS}

As sementes de $A$. sellowiana utilizadas neste estudo foram obtidas de frutos coletados em 2009, de duas plantas (G1 e G2) presentes em quintais da área urbana de Vacaria-RS (28 30'39' sul, 5055'47'" oeste e $950 \mathrm{~m}$ de altitude). Para confirmar tratarse de genótipos distintos, foram utilizados nove marcadores microssatélites (SANTOS et al., 2008) para sua genotipagem. Assim que colhidos, os frutos foram transportados ao Laboratório de Fisiologia do Desenvolvimento e Genética Vegetal (LFDGV), da Universidade Federal de Santa Catarina (UFSC), onde foram despolpados e separadas as sementes, adicionando-se enzima pectinase na proporção de 1,6 $\mathrm{mL} \mathrm{kg}^{-1}$ de polpa e mantidas por $48 \mathrm{~h}$ em temperatura ambiente (KASHYAP et al., 2001). Em seguida, as sementes foram lavadas em água corrente sobre uma peneira e secas à sombra por 12 horas. $\mathrm{O}$ peso de mil sementes (PMS) antes do armazenamento foi estimado mediante pesagem de quatro repetições de 50 sementes $(5,451 \mathrm{~g}$ e 4,420 g para G1 e G2, respectivamente).

$\mathrm{O}$ experimento envolveu três fatores, no esquema 2 × 3 × 2: condições de armazenamento (temperatura ambiente: $20-25^{\circ} \mathrm{C}$ em laboratório climatizado; e refrigerado: 4 a $8^{\circ} \mathrm{C}$ ), tempo de armazenamento (zero, um e dois anos) e genótipos (G1 e G2), organizados em blocos completos casualizados, com quatro repetições de 50 sementes. Quatro repetições de cada genótipo foram postas 
para germinar imediatamente (tratamento zero ano de armazenamento) e o restante das sementes foi embalado em 32 sacos de papel kraft contendo 50 sementes (16 sacos para cada genótipo) e armazenados. Para o armazenamento refrigerado, os sacos de papel foram envoltos em saco de polietileno $(0,015 \mathrm{~mm}$ de espessura, parcialmente permeável) e mantidos em geladeira. No tratamento com armazenamento em temperatura ambiente, os sacos de papel foram alocados em caixa de papelão e mantidos na bancada do laboratório, que apresentou umidade relativa variando entre 40 e $60 \%$.

Para o teste de germinação, as sementes foram previamente higienizadas com hipoclorito de sódio $(0,25 \%$ de cloro ativo na solução final), por 10 minutos, enxaguadas por duas vezes durante cinco minutos com água destilada (DUCROQUET et al., 2000) e postas para germinar sobre papel absorvente em caixas tipo "gerbox" esterilizadas. O papel foi previamente esterilizado e umedecido com água destilada na proporção de 2,5 vezes o peso. Cada "gerbox" continha uma repetição com 50 sementes, que foram mantidas em "fitotron", com temperatura de $25 \pm 2{ }^{\circ} \mathrm{C}$ e fotoperíodo de $16 \mathrm{~h}$.

As variáveis avaliadas foram índice de velocidade de germinação, porcentagem de germinação e tempo médio de germinação, conforme descrito por Gui-Ferreira e Borghetti (2004), sendo consideradas germinadas as sementes que apresentaram radícula com cinco ou mais milímetros de comprimento. As contagens de sementes germinadas foram realizadas a cada dois dias após o início da germinação, por um total de 44 dias. $\mathrm{Na}$ avaliação de vigor das sementes, tomaram-se como parâmetro o índice de velocidade de germinação e o tempo médio de germinação. A análise estatística consistiu em uma análise de variância e teste de Tukey $(p \leq 0,05)$ para comparação de médias. Previamente à análise da variância, os dados de percentagem foram transformados para arcsen $((x+1) / 100)^{1 / 2}$ e dados de índice de velocidade de germinação para $(x+0,5)^{1 / 2}$.

\section{RESULTADOS E DISCUSSÃO}

As sementes armazenadas em temperatura ambiente apresentaram queda drástica do índice de velocidade de germinação (de 2,06 para 0,28) e porcentagem de germinação (de 95,7\% para $21,7 \%$ ) entre o momento de colheita dos frutos (ano zero) e após um ano de armazenamento. Além disso, não houve germinação de sementes de goiabeira-serrana com dois anos de armazenamento em temperatura ambiente (Tabela 1). Quando armazenadas em ambiente refrigerado, o índice de velocidade de germinação também se reduziu ao longo do tempo, ao passo que a percentagem de germinação foi significativamente menor apenas com dois anos de armazenamento, em relação à germinação no ano zero. Porém, a germinação aos dois anos de armazenamento refrigerado mantevese acima de $80 \%$, o que pode ser considerada uma boa taxa de germinação, já que Wielewichi et al. (2006) encontraram, em média, 79,6\% de taxa de germinação logo após a colheita, ao estudar 624 lotes de 27 espécies florestais nativas da região Sul do Brasil.

Para outras espécies como o Cambuci (Campomanesia phaea), o armazenamento de sementes em ambiente natural por 240 dias também acarretou a perda completa de viabilidade, enquanto o armazenamento em geladeira com sementes envoltas em saco plástico manteve a viabilidade com $100 \%$ de germinação (MALUF; PISCIOTTANOEREIO, 2005). Por outro lado, sementes de Guabiju (Myrcianthes pungens) apresentaram perda completa da viabilidade após oito meses, mesmo com o armazenamento refrigerado (FIOR et al., 2010). Isto demonstra as diferenças existentes no comportamento fisiológico de sementes de diferentes espécies, embora da mesma família botânica, quando armazenadas. Portanto, cada espécie deve ser alvo de estudos específicos para obter métodos apropriados de conservação das sementes.

Essa perda de viabilidade com o armazenamento pode ser explicada pelo consumo das reservas disponíveis na semente (GUI-FERREIRA; BORGHETTI, 2004), ocorrendo mais lentamente nas sementes em armazenamento refrigerado devido à redução do metabolismo, em função da baixa temperatura. Possivelmente, as sementes armazenadas em temperatura ambiente também tenham reduzido mais o grau de umidade comparado ao armazenamento refrigerado (WALTERS, 2007), um fator ambiental que interfere na germinação de sementes armazenadas de goiabeira-serrana (GOMES et al., 2013).

Este comportamento de que após um ano de armazenamento, mesmo em temperatura ambiente, as sementes ainda mantiveram certa taxa de germinação, perdendo completamente a capacidade aos dois anos, não é incongruente com a classificação fisiológica de natureza intermediária (PAMMENTER; BERJAK, 1999) que está sendo sugerida para A. sellowiana (GOMES et al., 2013). Entretanto, Gomes et al. (2013) sugerem que sementes de goiabeira-serrana sejam de certo modo intolerantes ao armazenamento sob baixas temperaturas $\left(8^{\circ} \mathrm{C}\right)$ e que, em 90 dias nestas condições, há perda considerável do poder 
germinativo, o que diverge do encontrado no presente estudo. Isto pode ser influência da variabilidade genética, ou seja, dos distintos genótipos estudados, já que, no presente estudo, os genótipos tiveram desempenho diferenciado em relação ao poder germinativo e ao índice de velocidade de germinação (Tabela 1).

O tempo médio de germinação também foi influenciado pelo tempo e pelas condições de armazenamento. Após um ano de armazenamento das sementes, observou-se menor tempo médio de germinação das sementes mantidas refrigeradas $(26,3)$ comparativamente às mantidas em temperatura ambiente $(40,6)$. Para as sementes armazenadas em ambiente refrigerado, o tempo médio de germinação aumentou significativamente no segundo ano de armazenamento em relação ao ano anterior, de 26,3 para 27,5, respectivamente (Tabela 1). De acordo com Vieira e Carvalho (1994), é pressuposto que, quanto mais vigorosa é a semente, mais rápida é sua germinação. Isso sugere que, embora as sementes tenham mantido bom poder germinativo quando armazenadas em ambiente refrigerado, o consumo das reservas afetou o vigor das plântulas (GUIFERREIRA; BORGHETTI, 2004).

Os genótipos testados responderam de forma diferenciada ao armazenamento. As sementes oriundas do genótipo G2 apresentaram maiores índices de velocidade de germinação relativamente às do genótipo $\mathrm{G} 1$, de 1,39 contra 1,19 , respectivamente (Tabela 1). De acordo com Carvalho e Nakagawa (2000), sementes menores germinam mais rapidamente do que sementes maiores, devido à menor quantidade de água necessária para a embebição, podendo, assim, explicar a influência do tamanho das sementes no índice de velocidade de germinação, já que o peso médio de sementes obtido antes do armazenamento para G1 e G2 foi de 5,451 g e 4,420 g, respectivamente.

Da mesma forma, as sementes do genótipo G2 apresentaram maior porcentagem de germinação (Tabela 1). A variabilidade genética para essas características constitui-se em um dos fatores que influenciam as medidas de desempenho germinativo entre plantas da mesma espécie. Para mirtáceas, as diferenças entre genótipos quanto ao poder germinativo são conhecidas e ocorrem devido às diferenças de ambiente de coleta, variação genética entre plantas-matrizes e segregação genética na progênie (FIOR et al., 2010). Estudos em populações de goiabeira-serrana demonstraram a existência de alta diversidade genética na espécie, apresentando também altos níveis de heterose (SANTOS et al., 2009, 2011), o que deve ser levado em consideração para o armazenamento de sementes. Os dois genótipos utilizados no presente trabalho apresentaram quatro alelos em comum e diferiram nos demais 14 identificados, sendo, portanto, geneticamente distintos. Além disso, o fato de a espécie ser tipicamente de fecundação cruzada também sugere a existência de variação genética em suas progênies, e, desta maneira, estudos complementares seriam pertinentes para averiguar a magnitude da influência do genótipo sobre o vigor e a viabilidade de sementes após armazenamento.

Assim, considerando a finalidade do armazenamento de sementes de goiabeira-serrana, não é possível manter taxas aceitáveis de germinação (WIELEWICHI et al., 2006) por um ano com armazenamento em temperatura ambiente, o que foi verificado no presente trabalho, já que as sementes mantiveram, em média, $21,7 \%$ de germinação. Todavia, sob armazenamento refrigerado, foi possível manter, em média, 94,7\% de germinação com um ano e $80,6 \%$ com dois anos (Tabela 1). Este resultado permite recomendar o armazenamento refrigerado de sementes de goiabeira-serrana até dois anos após a colheita dos frutos, auxiliando no escalonamento da produção de mudas e em programas de melhoramento genético da espécie. 
TABELA 1 - Índice de velocidade de germinação, percentagem de germinação e tempo médio de germinação de sementes de dois genótipos (G1 e G2) de Acca sellowiana armazenadas por dois anos em temperatura ambiente e refrigerada $\left(4 \mathrm{a} 8^{\circ} \mathrm{C}\right)$. Florianópolis.

\begin{tabular}{|c|c|c|c|c|c|c|c|}
\hline \multirow[b]{2}{*}{ Ano } & \multicolumn{3}{|c|}{ Ambiente } & \multicolumn{3}{|c|}{ Refrigerado } & \multirow{2}{*}{ Média } \\
\hline & G1 & G2 & Média & G1 & G2 & Média & \\
\hline \multicolumn{8}{|c|}{ Índice de velocidade de germinação $(\mathrm{CV} \%=2,51)$} \\
\hline $\mathbf{0}$ & 1,93 & 2,19 & $2,06 \mathrm{aA}$ & 1,93 & 2,19 & $2,06 \mathrm{aA}$ & $2,06 \mathrm{~A}$ \\
\hline 1 & 0,20 & 0,36 & $0,28 \mathrm{bB}$ & 1,75 & 2,01 & $1,88 \mathrm{aB}$ & $1,08 \mathrm{~B}$ \\
\hline 2 & 0,00 & 0,00 & $0,00 \mathrm{bC}$ & 1,34 & 1,60 & $1,47 \mathrm{aC}$ & $0,74 \mathrm{C}$ \\
\hline Média & 0,71 & 0,85 & $0,78 b$ & 1,67 & 1,93 & $1,80 \mathrm{a}$ & 1,29 \\
\hline \multicolumn{4}{|c|}{ Média geral dos Genótipos } & $1,19 b$ & $1,39 \mathrm{a}$ & - & - \\
\hline \multicolumn{8}{|c|}{ Percentagem de germinação $(C V \%=4,52)$} \\
\hline $\mathbf{0}$ & 92,0 & 99,3 & $95,7 \mathrm{aA}$ & 92,0 & 99,3 & $95,7 \mathrm{aA}$ & $95,7 \mathrm{~A}$ \\
\hline 1 & 14,0 & 29,5 & $21,7 \mathrm{bB}$ & 93,5 & 96,0 & $94,7 \mathrm{aA}$ & $58,3 \mathrm{~B}$ \\
\hline 2 & 0,0 & 0,0 & $0,0 \mathrm{bC}$ & 72,9 & 88,2 & $80,6 \mathrm{aB}$ & $40,3 \mathrm{C}$ \\
\hline Média & 35,3 & 42,9 & $39,1 \mathrm{~b}$ & 86,1 & 94,5 & $90,3 \mathrm{a}$ & 64,7 \\
\hline \multicolumn{4}{|c|}{ Média geral dos Genótipos } & $60,7 b$ & $68,7 \mathrm{a}$ & - & - \\
\hline \multicolumn{8}{|c|}{ Tempo médio de germinação $(C V \%=2,48)$} \\
\hline 1 & 38,1 & 43,0 & $40,6 \mathrm{aA}$ & 27,7 & 24,9 & $26,3 \mathrm{bB}$ & $33,4 \mathrm{~A}$ \\
\hline 2 & 0,0 & 0,0 & $0,0 \mathrm{bB}$ & 27,5 & 27,5 & $27,5 \mathrm{aA}$ & $13,6 \mathrm{~B}$ \\
\hline Média & 19,1 & 21,5 & $20,3 b$ & 27,6 & 26,2 & $26,9 a$ & 23,6 \\
\hline \multicolumn{4}{|c|}{ Média geral dos Genótipos } & $23,3^{\text {ns }}$ & 23,9 & & - \\
\hline
\end{tabular}

Médias não seguidas pela mesma letra minúscula na linha e maiúscula na coluna diferem pelo teste de Tukey ( $\mathrm{p} \leq 0,05)$. Os dados de porcentagem foram transformados para arcsen $((x+1) / 100)^{1 / 2}$ e dados de índice de velocidade de germinação para $(x+0,5)^{1 / 2}$.

\section{CONCLUSÕES}

É possível conservar sementes de Acca sellowiana com armazenamento refrigerado (4 a $8{ }^{\circ} \mathrm{C}$ ) por dois anos, mantendo até $80 \%$ de poder germinativo.

Com o armazenamento em temperatura ambiente, o poder germinativo cai drasticamente após um ano e é perdido completamente aos dois anos.

O genótipo influencia o vigor e a germinação de sementes.

\section{AGRADECIMENTOS}

Agradecemos à FAPESC e ao $\mathrm{CNPq}$, pelos recursos financeiros, e ao $\mathrm{CNPq}$ e à $\mathrm{CAPES} /$ PIQDTec, pelas bolsas concedidas a RON, JD, TO e VP..

\section{REFERÊNCIAS}

BONTEMPO, P.; MITA, L.; MICELI, M.; DOTO, A. Feijoa sellowiana derived natural Flavone exerts anticancer action displaying HDAC inhibitory activities. The International Journal of Biochemistry \& Cell Biology, Oxford, v.39, p.1902-1914, 2007.

CARVALHO, N.M.; NAKAGAWA, J. Sementes: ciência, tecnologia e produção. 4.ed. Jaboticabal: FUNEP, 2000. 588p.

DELGADO, L.F.; BARBEDO, C.J. Tolerância à dessecação de sementes de espécies de Eugenia. Pesquisa Agropecuária Brasileira, Brasília, v.42, n.2, p.265-272, 2007.

DUCROQUET, J.P.H.J.; HICKEL, E.R.; NODARI, R.O. Goiabeira-serrana (Feijoa sellowiana). Jaboticabal: Funep, 2000. (Série Frutas nativas, 5) 
FAIAD, M.G.R.; SALOMÃO, A.N.; PADILHA, L.S.; MUNDIM, R.C. Sobrevivência de Colletotrichum gloeosporioides (Penz.) Sacc. em sementes de feijoa (Acca sellowiana Burr.) durante o armazenamento. Brasília: EMBRAPA, 2003. 4p. (Comunicado Técnico, 80).

FIOR, C.S.; RODRIGUES, L.R.; CALIL, A.C.; LEONHARDT, C; SOUZA, L.S.; SILVA, V.S. Qualidade fisiológica de sementes de guabijuzeiro (Myrcianthes pungens (Berg) Legrand - Myrtaceae) em armazenamento. Revista Árvore, Viçosa, MG, v.34, n.3, p.435-442, 2010.

GOMES, J.P.; OLIVEIRA, L.M.; SALDDANHA, A.P.; MANFREDI, S.; FERREIRA, P.I. Secagem e classificação de sementes de Acca sellowiana (O.Berg) Burret - Myrtaceae quanto à tolerância à dessecação e ao armazenamento. Floresta e Ambiente, Lages, v.20, n.2, p.2.015-2.017, 2013.

GUI-FERREIRA, A.G.; BORGHETTI, F. (Org.). Germinação: do básico ao aplicado. Porto Alegre: Artmed, 2004.

KASHYAP, D.R.; VOHRA, P.K.; CHOPRA, S.; TEWARI, R. Applications of pectinases in the commercial sector: a review. Bioresource Technology, New York, v.77, n.3, p.215-227, 2001.

KELLER, H.A.; TRESSENS, S.G. Presencia en Argentina de dos especies de uso múltiple: Acca sellowiana (Myrtaceae) y Casearia lasiophylla (Flacourtiaceae). Darwiniana, Buenos Aires, v.45, n.2, p.204-212, 2007.

MALUF, A.M.; PISCIOTTANO-EREIO, W.A. Secagem e armazenamento de sementes de Cambuci. Pesquisa Agropecuária Brasileira, Brasília, v.40, n.7, p.707-714, 2005.

MATTOS, J.R.A Goiabeira-serrana. Porto Alegre: Instituto de Pesquisas de Recursos Naturais Renováveis, 1986. (Publicação, 19)

NODARI, R.O.; SANTOS, K.L.; DUCROQUET, J.P.; GUERRA, M.P. Goiabeira-serrana: domesticação. In: BARBIERI, R.L.; STUMPF, E.R.T. (Org.). Origem e evolução de plantas cultivadas. Brasília: Embrapa Informação Tecnológica, 2008. p. 415-435.
PAMMENTER, N.W.; BERJAK, P. A review of recalcitrant seed physiology in relation to desiccation tolerance mechanisms. Seed Science Research, Cambridge, v.9, p.13-37, 1999.

SANTOS, C.M.R.; FERREIRA, A.G.; ÁQUILA, M.E.A. Características de frutos e germinação de sementes de seis espécies de Myrtaceae nativas do Rio Grande do Sul. Ciência Florestal, Santa Maria, v.14, n.2, p.13-20, 2004.

SANTOS, K.L.; DUCROQUET, J.P.H.J.; NODARI, R.O. Caracterização genética de populações naturais de goiabeira-serrana (Acca sellowiana) com marcadores microssatélites heterólogos. Biotemas, Florianópolis, v.24, n.4, p.75-83, 2011.

SANTOS, K.L.; GURIES, R.P.; NODARI, R.O.; PERONI, N. Traditional Knowledge and Management of Feijoa (Acca sellowiana) in southern Brazil. Economic Botany, New York, v.63, p.204214, 2009.

SANTOS, K.L.; LABOARDA, P.R.; SOUZA, A.P.; PERONI, N.; NODARI, R.O. Isolation and characterization of microsatellite markers in Acca sellowiana (Berg) Burret. Molecular Ecology Resources, Oxford, v.8, p.998-1000, 2008.

SAZIMA, I.; SAZIMA, M. Petiscos florais: pétalas de Acca sellowiana (Myrtaceae) como fonte alimentar para aves em área urbana no Sul do Brasil. Biota Neotropica, São Paulo, v.7, n.2, p.307-311, 2007.

THORP, G.; BIELESKI, R. Feijoas: origins, cultivation and uses. Auckland: HortResearch Ed. David Bateman, 2002.

VIEIRA, R.D.; CARVALHO, N.M. Testes de vigor em sementes. Jaboticabal: FUNEP, 1994.

VUOTTO, M.L.; BASILE, A.; MOSCATIELLO, V.; SOLE, P.; CASTALDO-COBIANCHI, R.; LAGHI, E.; IELPO, M.T.L. Antimicrobial and antioxidant activities of Feijoa sellowiana fruit. International Journal of Antimicrobial Agents, Amsterdam, v.13, p.197-201, 2000. 
WALTERS, C. Materials used for seed storage containers: response to Gomez-Campo. Seed Science Research, Kew, v.17, p.233-242, 2007. (1)
WIELEWICKI, A.P.; SCHLINDWEIN, G.; MEDEIROS, A.C.S. Proposta de padrões de germinação e teor de água para sementes de algumas espécies florestais presentes na região Sul do Brasil. Revista Brasileira de Sementes, Viçosa, v.28, n.3, p.191-197, 2006. (1) 